\title{
Inelastic Analysis of Semi-Rigid Composite Structures under Fire Conditions
}

This paper presents the application of a proposed numerical approach, denoted as SAAFE Program (System for Advanced Analysis for Fire Engineering), developed to provide an inelastic analysis of steel and composite (steel-concrete) $2 D$ semi-rigid framed-structures under fire conditions. The proposed structural model allows an accurate description of the structural non-linear response, with less computational effort when compared to the general FEM formulation. The method, although similar in concept to earlier plastic-hinge approaches, differs with regards to numerical implementation methodology and precision. The proposed plastic-hinge model is formulated in a succinct format based on the following characteristics: (i) a refined plastic lumped formulation with interaction surfaces, (ii) a tangent modulus model which includes both gradual inelastic loss of stiffness and ultimate strength of column members, (iii) a second-order large-displacement formulation, based on the Stability Functions concept, (iv) non-homogeneous temperature distribution over the cross-section, (v) a connection semi-rigid model. Obtained results for connection model calibration examples are compared to reported experimental data, showing reasonable agreement. In addition, results of a proposed case-of-study demonstrate the efficiency and robustness of the SAAFE model to perform inelastic analysis semi-rigid members, outlining the advantage of considering advanced analysis in the current fire-design practice of structures.

Keywords: fire safety, semi-rigid connections, plastic-hinge, second-order analysis

\section{Introduction}

Although concrete and steel are very different materials they can complement each other. The ideal combination of strengths - with concrete efficient in compression and steel in tension - can significantly enhance structural members by providing both strength and reduced size. As steel can improve resistance and speed of construction, concrete can provide corrosion protection and thermal insulation to steel at elevated temperatures. The extensive use of steel-concrete composite members, in order to increase fire survival of steel frames, can be evidenced by the availability of several current simplified design methods, such as: part 1.2 of the EC4 (EC4-1.2, 2003), the Appendix 4 of the American recommendation (AISC/LRFD, 2005) among others (ABNT-NBR8800, 2008).

Although the proposed code approaches are very straightforward to use, they possess many shortcomings in safe and economical design of structures in fire, e.g. checking is performed for isolated members only and a uniform temperature is assumed for steel members. For that reason, code equations are not able to describe the actual behavior of structures in fire, especially when global deformations are large and nonlinear behavior becomes relevant (Papadopoulos et al., 2008). In contrast, applications of sophisticated FEM-based (Finite Element Method) approaches have a significantly growth over the last decade (Huang et al., 2004, 2009; Franssen et al., 2005; Yu et al., 2008; Mourão and Silva, 2007), being able to simulate a complete structural system, including both thermal and mechanical responses to design-basis fire. Nevertheless, the amount of numerical data and the timeconsumption involved in the modeling process make it difficult to interpret the produced results.

Alternative technical solutions are still being demanded that could provide an accurate response, with less computational effort. In this regard, the original Advanced Analysis Concept (e.g., Chen et al., 1996) has been extended to study the global performance of steel framed structures subjected to compartment fires (Liew et al., 1998, 2002). Conversely, while a significant influence of

Paper received 8 April 2010. Paper accepted 1 July 2010. Technical Editor: Marcelo Savi connections on the behavior of framed buildings have been observed in real fires (Al-Jabri et al., 2005), and recently experimental programme (Yang et al., 2009, Daryan and Yahyai, 2009), the performed numerical simulation of the join region - already complex at room temperature - becomes further complicated under fire (Simões et al., 2001; Wang et al., 2008; Mao et al., 2010; Chung et al., 2010).

This paper is addressed to the development of an inelastic hingebased numerical tool, denoted as SAAFE Program (System for Advanced Analysis for Fire Engineering), able to perform material and geometric non-linearity analysis of 2D semi-rigid steel-concrete composite framed structures under fire conditions. The proposed plastic-hinge model, which has been previously implemented and validated for "rigid" composite framed structures (Landesmann et al., 2009; Landesmann, 2010) is adapted herein to assorted semirigid connections configurations under fire. The presented model is derived from inelastic moment-curvature-temperature-thrust response of composite elements under fire, representing a smooth transition from initial yield to full plastic domain under the interaction of axial and bending effects (Iu et al., 2007, 2009). In addition, the Component Method, originally proposed by part 1.8 of Eurocode 3 (EC3-1.8, 2003) to simulate the moment-rotation curve of connections, is modified and used in this paper to account the elevated temperatures effects. Moreover, the connection flexibility is evaluated as a function of the fire elapsed time and included in the beam-column element formulation.

In summary, section 2 of this paper presents the general formulation of SAAFE model, starting by describing the analysis methodology and the moment-rotation relationship of connection flexibility, to be evaluated as a function of the fire elapsed time. Obtained results of a proposed framed structure with different beamto-column support conditions are investigated by the SAAFE approach in section 3, in order to illustrate the efficacy of the proposed procedure for solving more complex structures under fire. In this section, results for a bolted end-plate connection are proposed and compared to experimental results (Al-Jabri et al., 2005), showing reasonable agreement. The main conclusions derived from the proposed implementations and results are presented in Section 4. 


\section{Nomenclature}

$A \quad=$ cross-section area, $\mathrm{cm}^{2}$

$A_{v c}=$ shear area of the column, $\mathrm{cm}^{2}$

$b_{\text {eff }}=$ effective width of each component, $\mathrm{cm}$

$E A=$ equivalent axial stiffness at $20^{\circ} \mathrm{C},{ }^{\circ} \mathrm{C}$

$E A_{\theta}=$ equivalent axial stiffness under fire, $k N$

EI = equivalent flexural stiffness at $20^{\circ} \mathrm{C}, \mathrm{kNcm}^{2}$

$E I_{\text {el }}=$ elastic flexural stiffness, $\mathrm{kNcm}^{2}$

$E I_{\theta}=$ equivalent flexural stiffness under fire, $\mathrm{kNcm}^{2}$

$E_{t} \quad=$ effective tangent modulus, $\mathrm{kN} / \mathrm{cm}^{2}$

$f_{c, 20}=$ characteristic compression concrete at $20^{\circ} \mathrm{C}, \mathrm{kN} / \mathrm{cm}^{2}$

$f_{c, \theta}=$ characteristic compression for concrete for fire, $\mathrm{kN} / \mathrm{cm}^{2}$

$F_{i . R d}=$ resistance of the $i$-th bolt row, $k N$

$f_{u b}=$ ultimate tensile strength of the bolts, $k N$

$f_{y, \theta}=$ yield stress for fire, $\mathrm{kN} / \mathrm{cm}^{2}$

$h_{i}=$ distance of bolt row from the center of compression, $\mathrm{cm}$

$K_{b} \quad=$ reduction factor for bolts, dimensionless

$K_{E}=$ reduction factor for young modulus, dimensionless

$K_{\phi} \quad=$ initial stiffness, $\mathrm{kNm} / \mathrm{rad}$

$K_{y}=$ reduction factor for Yield stress, dimensionless

$l_{b} \quad=$ bolt elongation length, $\mathrm{cm}$

$M \quad$ = bending moment, $\mathrm{kNcm}$

$m \quad=$ number of bolt rows in tension, dimensionless

$m_{c}=$ distance of bolt axis and the face of the web column, cm

$m_{e p}=$ distance of bolt axis and face of the weld, $\mathrm{cm}$

$M_{j, R d}=$ moment resistance, $\mathrm{kNcm}$

$M_{u}=$ ultimate flexional strength, $\mathrm{kNcm}$

$M_{u 20}=$ ultimate flexural strength for $20^{\circ} \mathrm{C}, \mathrm{kNcm}$

$M_{u \theta}=$ flexional equivalent plastic strength, $\mathrm{kNcm}$

$M_{\theta} \quad$ = flexural restoring forces, $\mathrm{kNcm}$

$n_{r} \quad=$ shape factor for moment-rotation curve, dimensionless

$P \quad=$ axial force, $k N$

$P_{u 20}=$ ultimate axial strength for normal temperature, $k N$

$P_{u \theta}=$ axial equivalent plastic strength, $k N$

$P_{\theta} \quad=$ axial restoring forces, $k N$

$R_{k t}=$ instant connection stiffness, $\mathrm{kN} / \mathrm{cm}^{2}$

$R_{k t i}=$ initial connection stiffness, $\mathrm{kN} / \mathrm{cm}^{2}$

$S_{1,2}=$ stability functions, $\mathrm{kN} / \mathrm{cm}^{2}$

$t \quad=$ thickness of the members, $\mathrm{cm}$

\section{Greek Symbols}

$\phi_{0}=$ permanent rotation of the joint, rad

$\gamma=$ partial safety factor, dimensionless

$\eta \quad=$ inelastic reduction factor, dimensionless

$\varepsilon_{\theta}=$ thermal expansion coefficient, dimensionless

$\theta \quad=$ temperature, ${ }^{\circ} \mathrm{C}$

$\psi \quad=$ incremental loading factor, dimensionless

\section{Subscripts}

$20=$ ambient temperature $\left(20^{\circ} \mathrm{C}\right)$

ep = end plate

$f_{c}=$ column flange

$w c=$ column web

$\theta \quad=$ fire conditions

\section{Proposed Numerical Analysis Approach}

\section{Basic assumptions and element formulation}

The proposed two-dimensional plastic-hinge model considers the following characteristics to be discussed in the presented section (Chen et al., 1996; Liew et al., 2002; Landesmann, 2010): (i) distributed plasticity effects described by a stiffness parameter $\eta$, evaluated as a function of the yielding progress at each plastic-hinge location, (ii) an approximate scheme based on an effective tangent- modulus $E_{t}$ concept, which reduces the modulus of elasticity in the element stiffness calculation, considering both the residual stress and out-of-straightness effects, and (iii) a second-order formulation based on conventional stability functions allowing an accurate identification of member instability with low computational efforts. The following assumptions are made for the stiffness formulation of the present approach: (i) the members are prismatic and slender in which the Bernoulli-Euler hypothesis is valid, (ii) lateral-torsional buckling, twisting effect, warping and shear deformations are neglected, (iii) nodal load response is only included in the present formulation, (iv) capacity of concrete under tension is negligible, (v) no separation between steel beam and concrete is allowed, and (vi) element is elastic and all material nonlinearities are allowed for in a plastic-hinge spring.

SAAFE program adopts a numerical procedure based on the Newmark integration scheme to account for the axial and the flexural inelastic mechanical responses, for different temperature distributions (Landesmann et al., 2009). In this procedure, a threeparameter power model originally proposed by Kishi-Chen (Chen et al., 1996) is used to represent the inelastic $M-\kappa$ (moment-curvature) curve, as given by Eq. (1). The following parameters are accounted for: (i) elastic stiffness $\left(E I_{e l}\right)$ evaluated from the tangent at $M-\kappa$ origin, (ii) ultimate flexional strength $\left(M_{u}\right)$, corresponding to the limit horizontal limit of $M-\kappa$, and (iii) an $n$ shape parameter.

$$
M(\kappa)=\frac{\kappa \cdot E I_{e l}}{\left(1+\left(\frac{\kappa \cdot E I_{e l}}{M_{u}}\right)^{n}\right)^{\frac{1}{n}}}
$$

The inelastic reduction factor $\eta$ concept, which represents the ratio between inelastic and elastic flexural stiffness (Chen et al., 1996), derived for composite structures under fire conditions (Landesmann, 2010) is given as follows (Eq. (2)), where $\left(E I_{e l}\right)$ is the elastic flexural stiffness.

$$
\eta=\frac{E I_{i n}}{E I_{e l}}=\frac{1}{E I_{e l}} \frac{d M(\kappa)}{d \kappa}=\frac{1}{\left[1+\left(\frac{\kappa \cdot E I_{e l}}{M_{u}}\right)^{n}\right]^{1+\frac{1}{n}}}
$$

The inelastic behavior of steel columns and composite (steelconcrete) at elevated temperature conditions, under pure axial compression (or for tension), is also simulated by SAAFE program (Landesmann et al., 2009). In this, the effective tangent modulus concept $\left(E_{t}\right)$ - previously developed to estimate the ultimate strength of compressed members for normal temperature conditions (Chen et al., 1996) - is adopted. The boundary surface approach (Liew et al., 2002) is computed by SAAFE to represent a smooth transition from the elastic to inelastic domain. In this procedure, an interaction $P-M$ surface is evaluated to capture the load combination of axial force $(P)$ and bending moment $(M)$. The computed $P-M$ interaction curves can be plotted for each time step of fire elapsed time.

The connections are modeled as rotational springs, physically tied to the ends of the elements, having the moment-rotationtemperature (in case of fire) curves described by the RambergOsgood (1943) relationship, given in the following section of this paper. The tangent stiffness of the connection $\left(R_{k t}\right)$, evaluated for each element end, is given by expression (Eq. (3)). 


$$
R_{k t}=\frac{d M}{d \phi_{r}}=\frac{K_{E} \cdot M_{j R d}}{\phi_{r}\left[1+n_{r}\left(\frac{M}{M_{j R d}}\right)^{n_{r}-1}\right]}
$$

The presence of the $K_{E}$ factor is used to account for the temperature influence and $M$ is the connection bending moment. The initial connection stiffness $\left(R_{k t i}\right)$ can be easily obtained by differentiating at the origin of the curve, as shown by Eq. (4).

$$
R_{k t i}=\left.\frac{d M}{d \phi_{r}}\right|_{M=0}=\frac{M_{j R d}}{\phi_{r}} K_{E}
$$

The cross-section ultimate resistances for normal temperature conditions $\left(20^{\circ} \mathrm{C}\right)$, denoted as $M_{u 20}$ and $P_{u 20}$, are modified taking into account the effective stress limit $\left(f_{u, \theta}: f_{y, \theta}\right.$ for steel and $f_{c, \theta}$ for concrete). The equivalent plastic strength, associated respectively with the axial $\left(P_{u \theta}\right)$ and flexional $\left(M_{u \theta}\right)$ strength are determined by Eq. (5).

$$
P u_{\theta}=\int_{A} \mathrm{f}_{\mathrm{u}, \theta} d A \quad M u_{\theta}=\int_{A} \mathrm{f}_{u, \theta}|y| d A
$$

The thermal deformations caused by the temperature increment are taken into account by a restoring forces vector approach. For a non-uniform temperature distribution along the cross-section, an axial $\left(P_{\theta}\right)$ and a flexural $\left(M_{\theta}\right)$ restoring force are evaluated (Eq. (6)), where $\varepsilon_{\theta}$ is the temperature-dependent thermal expansion coefficient (EC4-1.2, 2003).

$$
P_{\theta}=\int_{A} \varepsilon_{\theta} K_{E} E \cdot d A \quad M_{\theta}=\int_{A} \varepsilon_{\theta} K_{E} E \cdot y d A
$$

The element force-displacement relationship of a beam-column element with semi-rigid connections at its ends, implemented in SAAFE program, is expressed in terms of the stability functions, $S_{I}$ and $S_{2}$, derived from the beam-column equilibrium considerations (Chen et al., 1996), as presented by Eq. (7) to Eq. (11) and Fig. 1.

$$
\left\{\begin{array}{c}
\dot{M}_{A} \\
\dot{M}_{B} \\
\dot{P}
\end{array}\right\}=\frac{E I}{L}\left[\begin{array}{ccc}
S_{i i}^{*} & S_{i j}^{*} & 0 \\
S_{i j}^{*} & S_{j j}^{*} & 0 \\
0 & 0 & A / I
\end{array}\right]\left\{\begin{array}{c}
\dot{\phi}_{A} \\
\dot{\phi}_{B} \\
\dot{e}
\end{array}\right\}
$$

where the following terms are considered:

$$
\begin{aligned}
& S_{i i}^{*}=\frac{S_{i i}+\frac{E I \cdot S_{i i} \cdot S_{i j}}{L R_{k t B}}-\frac{E I \cdot S_{i j}^{2}}{L R_{k t B}}}{\left(1+\frac{E I \cdot S_{i i}}{L R_{k t A}}\right)\left(1+\frac{E I \cdot S_{j j}}{L R_{k t B}}\right)-\left(\frac{E I^{2}}{L}\right)\left(\frac{S_{i j}^{2}}{R_{k t A} R_{k t B}}\right)} \\
& S_{j j}^{*}=\frac{S_{i j}+\frac{E I \cdot S_{i i} \cdot S_{i j}}{L R_{k t A}}-\frac{E I \cdot S_{i j}^{2}}{L R_{k t A}}}{\left(1+\frac{E I \cdot S_{i i}}{L R_{k t A}}\right)\left(1+\frac{E I \cdot S_{j j}}{L R_{k t B}}\right)-\left(\frac{E I^{2}}{L}\right)\left(\frac{S_{i j}^{2}}{R_{k t A} R_{k t B}}\right)} \\
& S_{i j}^{*}=\frac{S_{i j}}{\left(1+\frac{E I \cdot S_{i i}}{L R_{k t A}}\right)\left(1+\frac{E I \cdot S_{i j}}{L R_{k t B}}\right)-\left(\frac{E I^{2}}{L}\right)\left(\frac{S_{i j}^{2}}{R_{k t A} R_{k t B}}\right)}
\end{aligned}
$$

$$
\begin{aligned}
& S_{i i}=\left[S_{1}-\frac{S_{2}^{2}}{S_{1}}\left(1-\eta_{B}\right)\right] \eta_{A} \\
& S_{j j}=\left[S_{1}-\frac{S_{2}^{2}}{S_{1}}\left(1-\eta_{A}\right)\right] \eta_{B} \\
& S_{i j}=\eta_{A} \eta_{B} S_{2}
\end{aligned}
$$

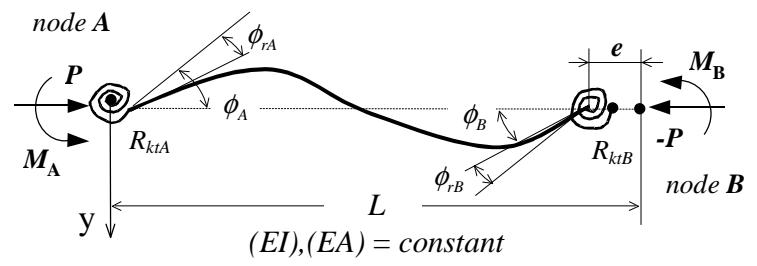

Figure 1. Beam-column element with end connections.

The equivalent axial $(E A)$ and flexural $(E I)$ stiffness are replaced by the respective terms under fire: $\left(E A_{\theta}\right)$ and $\left(E I_{\theta}\right)$, which are evaluated as a function of the fire elapsed time, accounting for the corresponding temperature distribution on the basis of the temperature-dependent elastic modulus, as follows (Eq. (12)):

$$
E A_{\theta}=\int_{A} K_{E} E \cdot d A \quad E I_{\theta}=\int_{A} K_{E} E \cdot y^{2} d A
$$

\section{Connection component modeling}

The Component Method is a simplified analytical model used to represent the moment-rotation curve of several connection typologies. This approach is based on a mechanical model introduced by EC3 1.8 (2003) and has been extensively correlated to experimental data as presented by Faella et al. (2000). In this model, the joint is assumed as assembly of extensional springs (components), with predefined characteristics of stiffness and resistance that might contribute to the joint deformation. The identification of the active components of the joint is the first step of the method. After that, the force-deformation relationship for each individual component can be established. Finally, a connection moment-rotation curve can be proposed, where the basic following parameters are normally used to define the joint behavior: initial stiffness $\left(K_{\phi}\right)$, moment resistance $\left(M_{j, R d}\right)$ and the permanent rotation $\left(\phi_{0}\right)$. This paper is concerned with steel bolted beam-to-column endplate connections under ambient and fire conditions, where 8 active components are identified, as presented in Fig. 2(a).

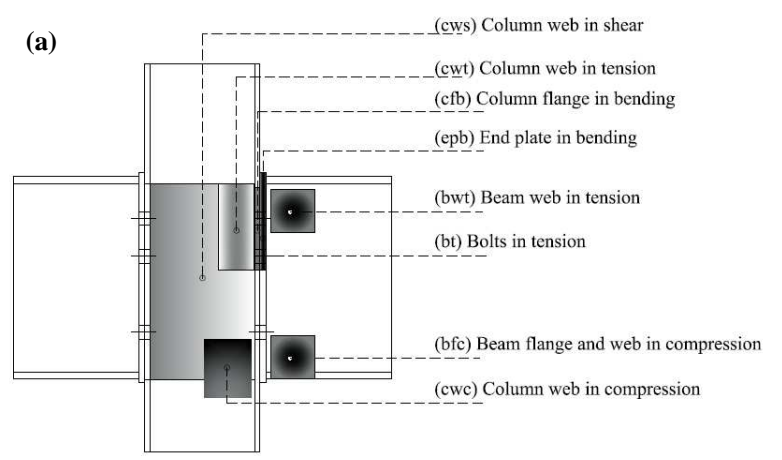


(b)

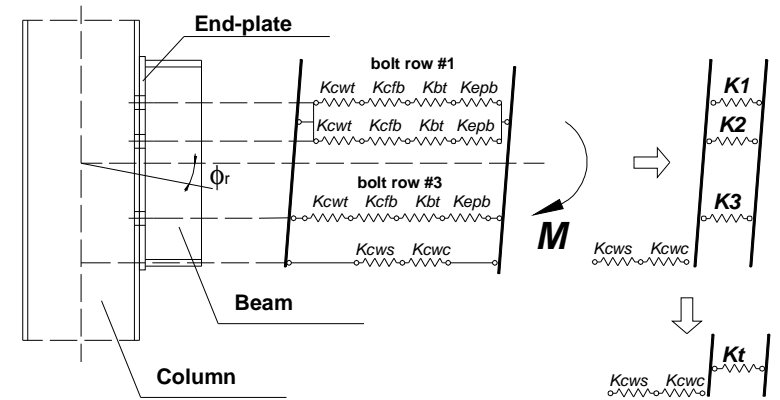

Figure 2. (a) Active components for bolted beam-to-column end-plate connections and (b) joint rotational stiffness according to EC3-1.8 (2003).

The components related to "beam flange and web in compression" ( $b f c)$ and "beam web in tension" (bwt) are considered in the flexural strength of the joint. The remaining components (total of 6) are assumed to have a perfectly-plastic behavior. Some of these components depend on the number of bolt row in tension and of its location on the joint. As for instance in the case of the column web in tension, column flange in bending, end plate in bending, bolts in tension and beam flange in tension. The contribution of these components has to be assessed considering the behavior of each individual bolt row and the group effect, i.e., considering the possible interaction with other bolt rows (Faella et al., 2000). The mechanical model suggested by EC3 1.8 (2003) is presented in Fig. 2(b). The main steps of the procedure, used to evaluate the joint rotational stiffness (EC3-1.8, 2003), are also summarized in Fig. 2(b), where the stiffness of each component is represented by a spring with predefined characteristics.

The joint flexural resistance $M_{j R d}$ is computed by Eq. (13), where $F_{i . R d}$ is the resistance of the $i$-th bolt row, $m$ is the number of bolt rows in tension (total of 3 ) and $h_{i}$ is the distance of the bolt row from the center of compression, which is located in the midthickness of the beam compressed flange. The procedure starts by evaluating the last bolt row from the center of compression, repeating the process for each other bolt row.

$$
M_{j R d}=\sum_{i=1}^{m} h_{i} F_{i R d}
$$

The resistance of each bolt row is obtained by considering the weakest value between the strength of their basic components. It should be noted that the resistance of any bolt group cannot exceed the resistance of the components, which are independent of the bolt rows. For the initial stiffness, Eq. (14), the general stiffness of the joint is obtained by combining the extensional stiffness of individual components. So that, the equivalent overall stiffness of the tension bolt rows given by Eq. (16) is obtained. In this procedure, a rigid rotation of the beam web around the compression center is assumed, presenting the lever arm in Eq. (15). The strength and initial stiffness for the main connection components are summarized in Table 1 (EC3-1.8, 2003).

$$
\begin{aligned}
& K_{\phi}=\frac{\frac{h_{t}^{2}}{K_{c w s}}+\frac{1}{K_{c w c}}+\frac{1}{K_{t}}}{h_{t}=\sum_{i=1}^{m} \frac{K_{i} h_{i}^{2}}{K_{i} h_{i}}} \\
& K_{t}=\sum_{i=1}^{m} \frac{K_{i} h_{i}}{h_{t}}
\end{aligned}
$$

\section{Moment-rotation behavior}

The non-linear Ramberg-Osgood (1943) relationship is used in this paper to represent the moment-rotation curve of the proposed connections under fire conditions, as presented by Eq. (17), where $\phi_{0}$ is the permanent rotation of the joint, given by Eq. (18), $n_{r}$ is a shape factor characterizing the knee of the moment-rotation curve, $K_{E}$ is the young's modulus reduction factor as a function of the temperature (Fig. 3(b)) and $M$ is the connection loading bending moment.

$$
\begin{aligned}
& \phi_{r}(M)=M \frac{\phi_{0}}{M_{j R d}}\left(\frac{1}{K_{E}}\right)\left[1+\left(\frac{M}{M_{j R d}}\right)^{n_{r}-1}\right] \\
& \phi_{0}=\frac{M_{j R d}}{K_{\phi}}
\end{aligned}
$$

Table 1. Design values for the response of components.

\begin{tabular}{|c|c|c|}
\hline Component & Strength & Stiffness \\
\hline $\begin{array}{c}\text { Column web } \\
\text { in shear }\end{array}$ & $V_{c w s . R d}=\frac{f_{y w c} A_{v c}}{\sqrt{3} \gamma_{M 0}}$ & $K_{c w s}=\frac{G A_{v c}}{\beta h_{t}}$ \\
\hline $\begin{array}{c}\text { Column } \\
\text { flange in } \\
\text { bending }\end{array}$ & $\begin{array}{c}T \text {-sub Eq. 6.2.6.4 } \\
\text { (EC3-1.8, 2003) }\end{array}$ & $K_{c f b}=E \frac{0.85 b_{e f f . c f b} t_{f c}{ }^{3}}{m_{c}{ }^{3}}$ \\
\hline $\begin{array}{c}\text { Column web } \\
\text { in tension }\end{array}$ & $F_{c w t . R d}=b_{e f f . c w t} t_{w c} f_{y w c} \rho$ & $K_{c w t}=E \frac{0.7 b_{e f f . c w t} t_{w c}}{d_{w c}}$ \\
\hline $\begin{array}{c}\text { End plate in } \\
\text { bending }\end{array}$ & $\begin{array}{c}T-s u b E q .6 .2 .6 .5 \\
(\mathrm{EC} 3-1.8,2003)\end{array}$ & $K_{e p b}=E \frac{0.85 b_{e f f . e p} t_{e p}{ }^{3}}{m_{e p}{ }^{3}}$ \\
\hline $\begin{array}{c}\text { Bolts in } \\
\text { tension }\end{array}$ & $F_{t . R d}=\frac{0.9 f_{u b} A_{s}}{\gamma_{M b}}$ & $K_{b}=E \frac{1.6 A_{b}}{l_{b}}$ \\
\hline $\begin{array}{c}\text { Column web } \\
\text { compression }\end{array}$ & $F_{c w c . R d}=\frac{b_{e f f . c w c} t_{w c} f_{y w c} \rho k_{c w c}}{\gamma_{M 0}}$ & $K_{c w c}=E \frac{0.7 b_{e f f . c w c} t_{w c}}{d_{w c}}$ \\
\hline
\end{tabular}

The proposed connection parameters are outlined in Fig. 3(a) by means of the Ramberg-Osgood relationship in comparison to the simplified bi-linear moment-rotation curve, proposed by EC3-1.8 (2003), where $R_{k t}$ is the instant connection stiffness. The degradation of structural steel with increasing temperature $(\theta)$ is characterized by a reduction of yield stress by the coefficient $K_{y}$ according to EC4-1.2 (2003), as shown in Fig. 3(b), where $K_{b}$ is the stiffness coefficient reduction for bolts ( $K_{E}$ is the young's modulus reduction factor).

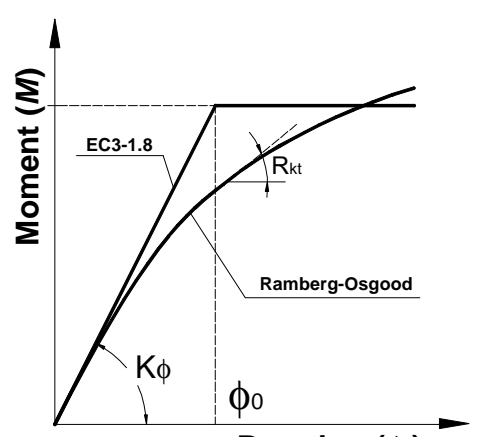

Rotation $\left(\phi_{r}\right)$ 


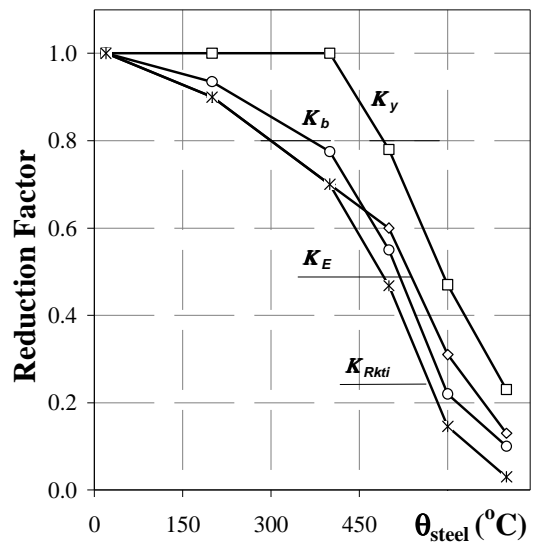

(b)

Figure 3. (a) Connection moment-rotation representation, and (b) reduction factors for steel components at elevated temperature (EC4-1.2, 2003).

\section{Thermo-mechanical properties for fire conditions}

The temperature response of members exposed to fire is performed by SAAFE program by 2D FEM nonlinear transient heat transfer analysis (Cook et al., 2002). The thermal temperaturedependent properties of materials are considered in accordance to EC4-1.2 (2003). Fire exposed members are assumed to be uniformly heated along the entire length and around the entire perimeter of the exposed section. A resultant emissivity value of 0.5 and 0.7 , respectively for steel and concrete surfaces, are assumed for the radiative heat flux, where a heat transfer coefficient of $25 \mathrm{~W} /{ }^{\circ} \mathrm{C} \cdot \mathrm{m}^{2}$ is assumed for convective flux. The effects of non-uniform temperature distribution in the cross-section (Guo and $\mathrm{Li}, 2008$ ) are accounted for in the present approach. As recommended by EC4-1.2 (2003), the temperature for the connection is assumed to be uniform and equal to the mean temperature of the bottom flange of the mid spam of beams elements supporting any type of concrete floor. Based on the temperature distribution of the cross-section, the structural thermal effects are automatically accounted for by SAAFE program. The variation of the mechanical properties of the cross-section, i.e. the effective strength and stiffness as a function of the fire elapsed time (also temperature) are performed, taking into account the stress-strain $(\sigma v s . \varepsilon)$ relationship for concrete and steel at elevated temperatures, as proposed by EC4-1.2 (2003).

\section{Application Example}

\section{General description}

A 2-storey 3-bay portal-framed structure is proposed in this paper (Fig. 4(a)) to verify the connection influence on the structural behavior under fire conditions. The column elements are composed of four $2 \times 3 \mathrm{~m} \mathrm{UC} 152 \times 152 \times 23$ section and three $8 \mathrm{~m}$ spans of a UB $254 \times 102 \times 22$. The composite behavior is considered for the proposed beam elements, assuming full interaction between the steel profile and a $10 \mathrm{~cm}$ thick concrete slab, poured-in-place $\left(f_{c, 20}=20 \mathrm{MPa}\right.$, characteristic compression for $\left.20^{\circ} \mathrm{C}\right)$. The reinforcement bars in the slab are not considered in the beam design. The following S275 steel mechanical properties are considered in the analysis: $f_{y, 20}=322 \mathrm{MPa}$ and $E=197 \mathrm{kN} / \mathrm{mm} 2$ for $20^{\circ} \mathrm{C}$, as experimentally measured by Al-Jabri et al. (2005). A standard firedesign curve (EC1-1.2, 2001) is postulated to occur at the first floor, between columns 2 and 3, as also indicated in Fig. 4(a).

Only the lower parts of the beams are partially exposed to fire, while the columns are assumed to be fully protected against fire action (Fig. 4(a)). A steady-state external mid-span loading force
( $\mathrm{F}=7.9 \mathrm{kN})$, corresponding to $20 \%$ of the ultimate nominal flexural strength of the downstand beam is considered in the analysis. Three conditions are assumed for the beam-to-column connections: (i) rigid, (ii) pinned and (iii) semi-rigid. Constructional details for the semi-rigid connection are presented in Fig. 4(b).

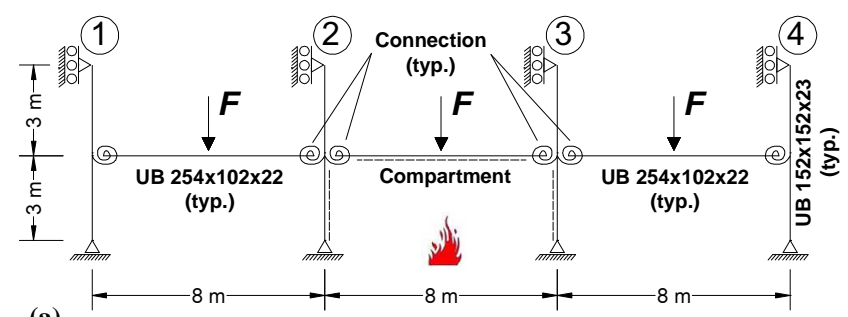

(a)

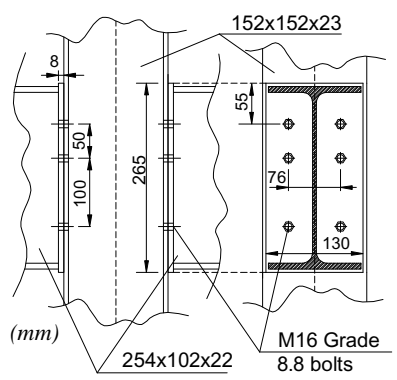

(b)

Figure 4. (a) Definition for the proposed 2-storey portal-framed, and (b) join details (Al-Jabri et al., 2005).

\section{Thermo-mechanical response}

The inelastic mechanical response of composite elements under fire conditions, previously presented in this paper, is applied in this section for the analysis of the composite UB $254 \times 102 \times 22$ beam element. The evaluated temperature response of the proposed element is presented in Fig. 5(a), in which three points are selected to represent the temperature across the section height. A $40 \mathrm{~mm}$ thick insulation layer is considered for the steel beam. The following insulation properties are taken into account: density of $800 \mathrm{~kg} / \mathrm{m}^{3}$, specific heat $1700 \mathrm{~J} / \mathrm{kg}^{\circ} \mathrm{C}$ and thermal conductivity of $0.17 \mathrm{~W} / \mathrm{m}^{\circ} \mathrm{C}$. The maximum temperature is observed to occur at the lower flange $\left(\theta_{3}\right)$, followed by the web $\left(\theta_{2}\right)$ and the top flange $\left(\theta_{1}\right)$, since this last point is partially protected by the concrete slab. The standard firedesign curve is also plotted in order to compare the temperature evolution on steel and at the contour medium. The changing of the ultimate composite section strength, $P-M$ interaction curves, as a function of the fire elapsed time, can be verified in Fig. 5(b) - where the compression-positive bending moment combination curves (lower flange in tension) can be seen.

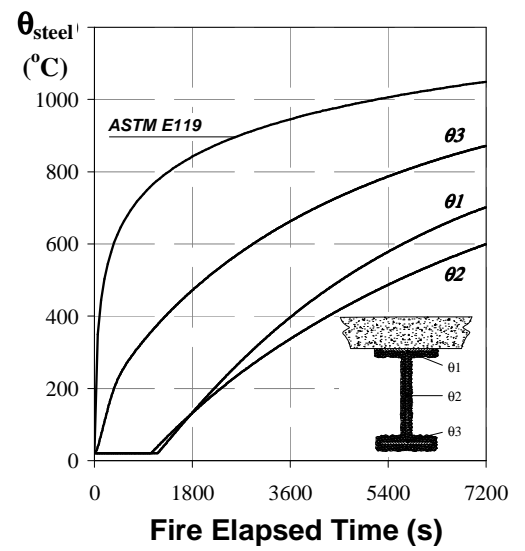

(a)

\section{J. of the Braz. Soc. of Mech. Sci. \& Eng. Copyright ( $\quad 2011$ by ABCM}

October-December 2011, Vol. XXXIII, No. 4 / 487 


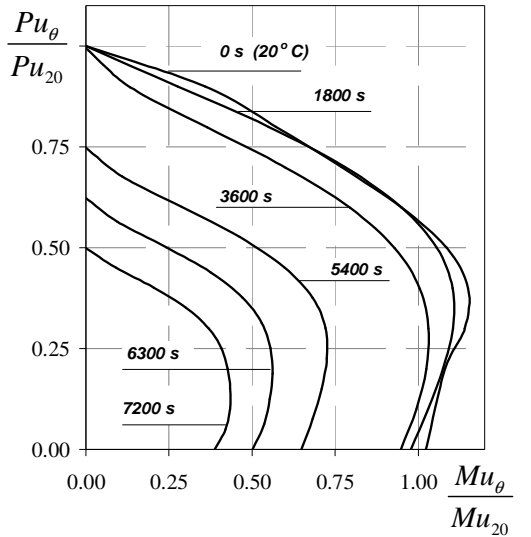

(b)

Figure 5. Thermo-mechanical response for UB 254 composite beam as a function of fire elapsed time: (a) temperature and, (b) boundary surface.
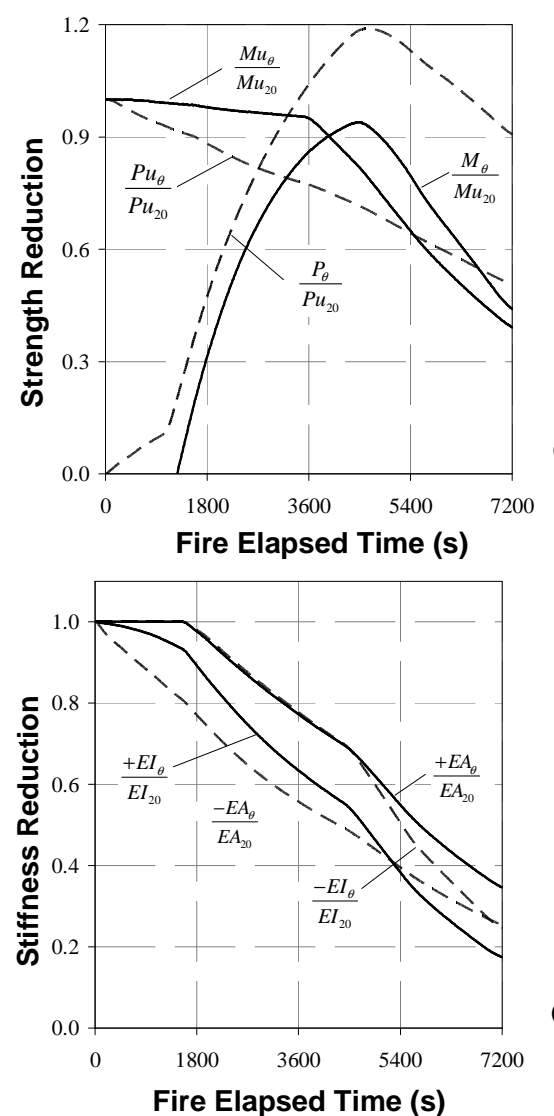

(d)

Figure 5 (continuation). Thermo-mechanical response for UB 254 composite beam as a function of fire elapsed time: (c) strength and, (d) stiffness reductions.

Due to the interaction between steel-concrete composite behavior as well as the presence of the insulation layer, a strength reduction less than $10 \%$ is observed for the first hour of fire, in comparison to ambient temperature section capacity. In addition to Fig. 5(b), the variation of the equivalent plastic strength, associated respectively with the axial $\left(P_{u \theta}\right)$ and flexional $\left(M_{u \theta}\right)$ strength, given by Eq. (5), is presented in Fig. 5(c), normalized by the corresponding capacity for normal temperature conditions. As shown, the section inelastic capacity is continuously reduced as a function of the fire elapsed time. It should be noted that there is a considerable change in the flexural behavior after $1 \mathrm{~h}$-fire. The equivalent cross-section restoring forces for axial $\left(P_{\theta}\right)$ and flexural $\left(M_{\theta}\right)$ effects, previously given by Eq. (6), are also presented in Fig. 5(c). The modification of the element axial and flexural stiffness as function of the fire elapsed time, respectively $E A$ and $E I$, is given in a normalized form by Fig. 5(d). Where, one can observe the influence of the compression and tension behavior on the element stiffness, as a function of the fire elapsed time.

In order to verify the applicability of the proposed component model, previously presented in this paper, a cruciform bolted endplate steel joint configuration, experimentally tested by Al-Jabri et al. (2005) is selected. The joint details, previously given in Fig. 4(b), consist of two UB $254 \times 102 \times 22$ beams connected to a UC $152 \times 152 \times 23$ column by an $8 \mathrm{~mm}$ thick flush end plate and six M16 grade 8.8 bolts. The connection moment-rotation $\left(M-\phi_{r}\right)$ curves for different uniform temperature distribution across the joint are presented in Fig. 6(a), where one can observe good agreement between the experimental results (Al-Jabri et al., 2005) and the presented component model approach, previously given by Eq. (17).

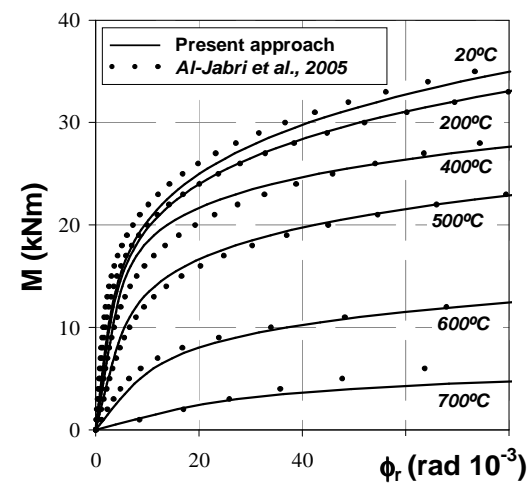

(a)

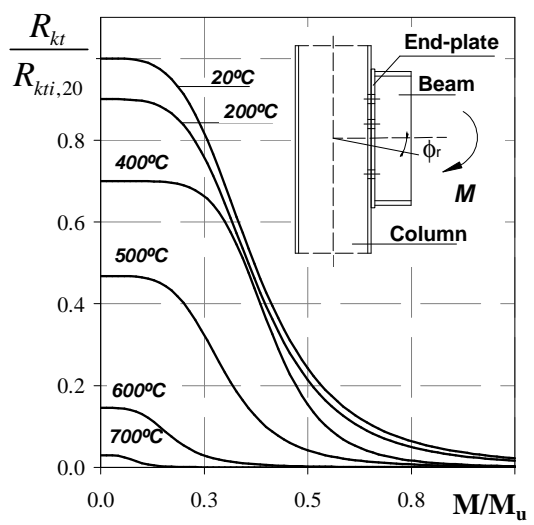

(b)

Figure 6. Connection behavior under fire conditions: (a) moment-rotation $\left(\boldsymbol{M}-\phi_{r}\right)$ and, (b) variation of the connection tangent stiffness $\left(\boldsymbol{R}_{k t} / \boldsymbol{R}_{k t i 20}\right)$.

The variation of the normalized connection tangent stiffness (in a normalized form: $R_{k} / R_{k t i, 20}$ ), previously presented by Eq. (3), for different bending moments, is given by Fig. 6(b), where, $R_{k t i, 20}$ is the initial connection stiffness for ambient temperature conditions and $M_{u}$ is the connection ultimate flexural capacity. The variation of the $R_{k t i}$, which represents the initial branch of the $R_{k t}$, as a function of the steel temperature is previously presented in Fig. 3(b). This curve is plotted in comparison to the steel reduction factors provided by EC4-1.2 (2003), also given in Fig. 3(b). The variables, presented by Eq. (17), to represent Ramberg-Osgood (1943) moment-rotation relationship for the proposed end-plate connection under fire conditions, are summarized in Table 2. The proposed values for the connection shape parameter $n_{r}$ were obtained by curve-fitting the proposed Ramberg-Osgood approach with experimental results from Al-Jabri et al. (2005). 
Table 2. Proposed values for the Ramberg-Osgood (1943) momentrotation relationship of end-plates connections at elevated temperatures.

\begin{tabular}{|c|c|c|c|c|}
\hline $\begin{array}{c}\text { Connection } \\
\text { temperature }\end{array}$ & $\begin{array}{c}\boldsymbol{K}_{\boldsymbol{\phi}} \\
(\mathbf{k N m} / \mathbf{r a d})\end{array}$ & $\begin{array}{c}\boldsymbol{M}_{\boldsymbol{j} \boldsymbol{R} \boldsymbol{d}} \\
(\mathbf{k N m})\end{array}$ & $\begin{array}{c}\boldsymbol{\phi}_{\boldsymbol{D}} \\
\left(\mathbf{1 0}^{-3} \mathbf{r a d}\right)\end{array}$ & $\boldsymbol{n}_{\boldsymbol{r}}$ \\
\hline $20^{\circ} \mathrm{C}$ & 4380 & 19.60 & 4.47 & 5.5 \\
\hline $200^{\circ} \mathrm{C}$ & 3942 & 19.60 & 4.97 & 5.5 \\
\hline $400^{\circ} \mathrm{C}$ & 3066 & 19.60 & 5.39 & 6.5 \\
\hline $500^{\circ} \mathrm{C}$ & 2628 & 15.29 & 5.82 & 5.5 \\
\hline $600^{\circ} \mathrm{C}$ & 1358 & 9.21 & 6.78 & 5.5 \\
\hline $700^{\circ} \mathrm{C}$ & 570 & 4.51 & 7.91 & 5.5 \\
\hline
\end{tabular}

\section{Structural behavior}

Since the inelastic properties of the elements and connection are evaluated, the structural behavior of the proposed 2 storey framed (Fig. 4) can be assessed for ambient and fire conditions. Results for the vertical displacement, evaluated at the mid-spam of the central beam (axes 2-3), are given by Fig. 7 for the proposed beam-to-column connections cases: pinned, semi-rigid and rigid, where the influence of the joint flexibility can be compared, for fire conditions as well as for ambient temperature, respectively given by Fig. 7(a) and Fig.7(b). In this last case, an incremental loading factor $(\psi)$ is considered, where $\psi=1$ is assumed to be the ultimate capacity of the pinned connection. The performed analysis considered thermal effects as well as the external loading.

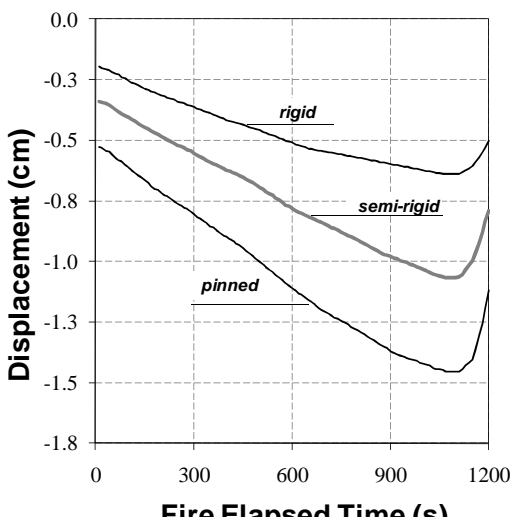

(a)

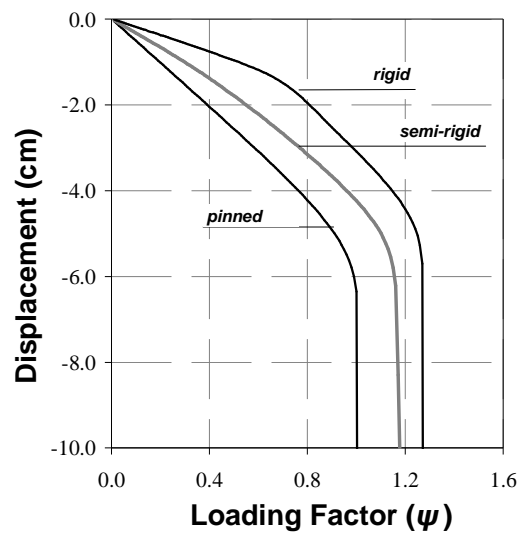

(b)

Figure 7. Vertical mid-spam displacement of the proposed 2-storey portalframed for different beam-column connections cases: (a) for high temperature conditions, as a function of the fire elapsed time and (b) for normal conditions, as a function of the mechanical loading factor $(\psi)$.

In order to infer about the flexural inelastic behavior of distinct cross-section configurations, two additional simplified numerical cases have been proposed. Each case consists of an isolated $8 \mathrm{~m}$ span beam member, where the beam cross-section configuration proposed for the 2-storey portal-framed is used. This isolated member is analogous to an individual bay of the 2-storey portal-framed. The vertical load is continuously incremented by small load-steps until no numerical convergence is obtained, which is interpreted as the member failure. Two boundary conditions are verified on this proposed analysis: (i) simply-supported and (ii) fully-restrained. The adopted modelling discretization is similar to the one proposed for the 2 -storey portal-framed beams. A comparison between the mid-span vertical displacements $(\delta y)$, obtained by both SAAFE and FEM (Franssen et al., 2005) approaches are presented in Fig. 8(a) for simply-supported and fully-restrained boundary conditions.

The nonlinear behavior of each configuration can be followed up to the member failure, in which, the correspondent applied load level can be verified. The inelastic effects associated with the presence of plastic-hinge zones along the member, represented by means of approximated plastic-hinge indices $\eta \%$ (Eq. (2)) are illustrated in Fig. 8(b). Both simply-support and fully-restrained computed conditions are contrasted - each plastic failure mechanism can be recognized as well as the correspondent ultimate load capacity. As observed in Fig. $8(\mathrm{a})$, the proposed SAAFE approach is able to mainly capture nonlinear load-displacement trajectories estimated by FEM model (Franssen et al., 2005), showing very good agreement either for the elastic range and the ultimate capacity of the elements. As indicated in Fig. $8(\mathrm{a}, \mathrm{b})$, for the simply-supported case, the progressive erosion in the element stiffness caused by the plastic process results in a nonlinear behavior. As expected, the fully-restrained case is able to account for a higher ultimate load level.
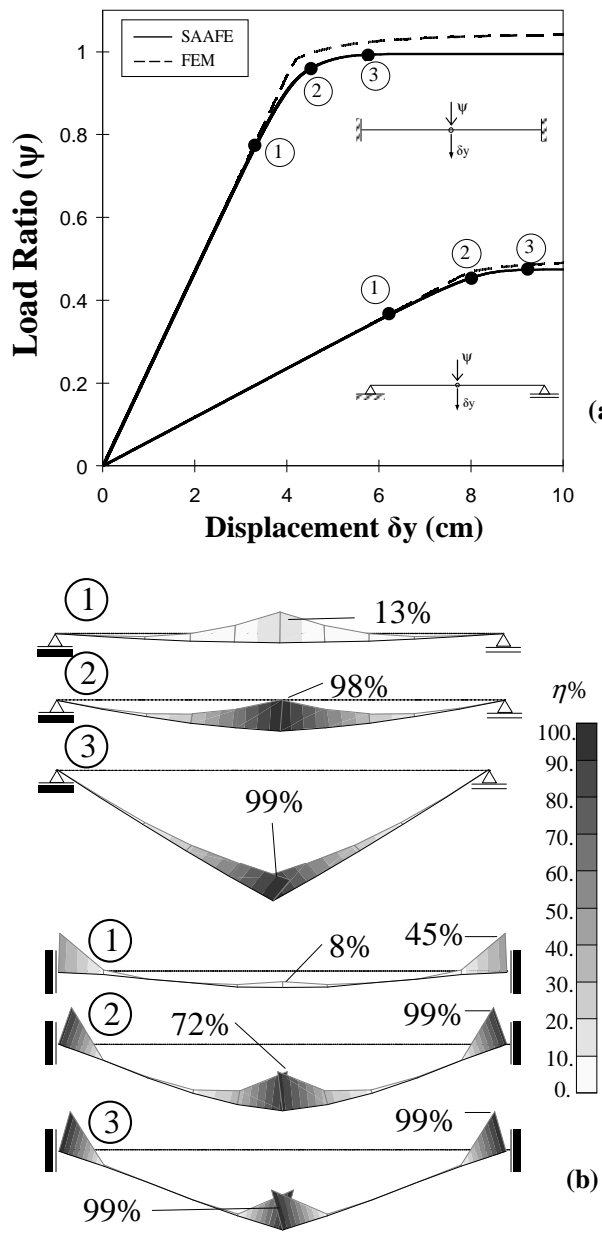

Figure 8. (a) Comparison of load-displacement results for isolated beams and, (b) correspondent inelastic index for different load levels. 
The nonlinear structural behavior of the 3-storey frame under fire condition is presented in Fig. 9. One can observe the frame deformed configuration for the proposed beam-to-column connection cases. It is possible to compare three selected fire instants: $600 \mathrm{~s}, 1000 \mathrm{~s}$ and $1500 \mathrm{~s}-$ respectively given by Fig. 8 . The presented structural displacements are multiplied by 30 . As expected, the pinned case presents the higher beam deformations when compared to those of the semi-rigid and fixed cases.
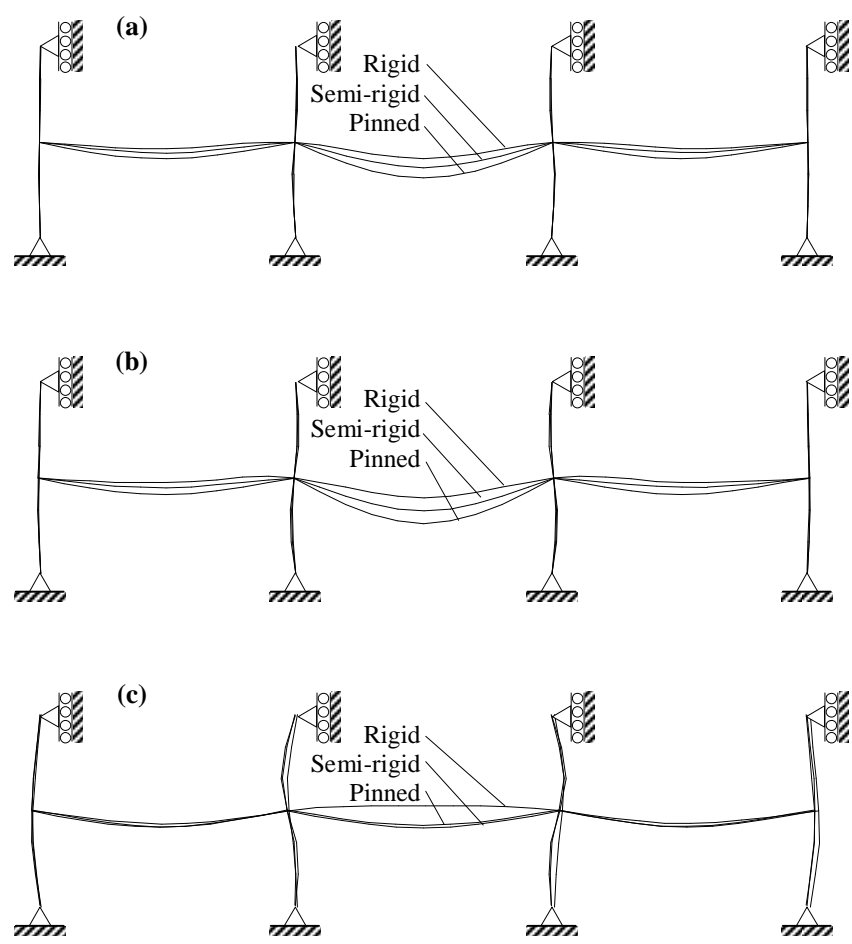

Figure 9. Nonlinear structural behavior of the 3-storey frame under fire conditions at 3 time steps: (a) 600 s, (b) 1000 s, (c) 1500 s.

\section{Conclusions}

A second-order refined plastic hinge analysis method, used to assess the performance of steel and composite (steel-concrete) structures under fire conditions, previously validated for continuous frames (Landesmann, 2010), is presented in this paper for semi-rigid connections. The computational approach, SAAFE Program (Landesmann et al., 2009), has been developed based on the Advanced Analysis concept (Chen et al., 1996), taking into account the non-linear behavior of material at elevated temperatures, as recommended by part 1.2 of Eurocode 4 (EC4-1.2, 2003). The analytical model was used in this paper to study the behavior of semirigid connections under fire. In this regard, a case study for end-plate connections at elevated temperature based on the Component Method (EC3-1.8, 2003) was presented. Results for the joint behavior were compared with experimental data reported by Al-Jabri et al. (2005) with acceptable agreement. A function for the connection tangent stiffness for different temperatures levels, derived from the basic moment-rotation relationship (Ramberg-Osgood, 1943), was obtained and included in the beam-column element formulation. Results for a proposed 2-storey portal-framed structure indicate that the proposed approach is able of predicting the inelastic performance of steel and composite structures under fire, avoiding a complex modeling representation for the beam-column elements and connections.

\section{References}

Al-Jabri, K.S., Burgess I.W., Plank R.J., 2005 "Spring-Stiffness Model for Flexible End-Plate Bare-Steel Joints in Fire", Journal of Constructional Steel Research, Vol. 61, pp. 1672-1691.

American Institute of Steel Construction, 2005, "Manual of Steel Construction - Load and Resistance Factor Design Specification for Structural Steel Buildings - AISC/LRFD", Chicago/EUA.

Brazilian Association of Technical Standards, 2008, "Project and Execution of Steel Buildings Structures - ABNT-NBR8800”, Rio de Janeiro, Brazil (in Portuguese).

Chen, W.F., Goto, Y., and Liew, J.Y.R., 1996, "Stability Design of Semi-Rigid Frames", John Wiley and Sons, New York.

Chung, S.Y., Lee, C.H., Su, W.J., and Lin, R.Z., 2010, "Application of fireresistant steel to beam-to-column moment connections at elevated temperatures", Journal of Constructional Steel Research, Vol. 66, No. 2, pp. 289-303.

Comité Européen de Normalisation (CEN), 2001, "Eurocode 1: Actions on Structures, Part 1-2: Actions on Structures exposed to Fire", Brussels.

Comité Européen de Normalisation (CEN), 2003, "Design of Steel Structures, Part 1-8: General Rules Design of Joints", Brussels.

Comité Européen de Normalisation (CEN), 2004, "Design of Composite Steel and Concrete Structures, Part 1-2: General Rules Structural Fire Design”, Brussels.

Cook, R.D., Malkus, D.S., Plesha, M.E., and Witt, R.J., 2002, "Concepts and Applications of Finite Element Analysis", $4^{\text {th }}$ Ed., John Wiley and Sons, NY.

Daryan, A.S., and Yahyai, M., 2009, "Behavior of beam-to-column moment connections under fire load", Journal of Constructional Steel Research, Vol. 65, No. 7, pp. 1520-1527.

Faella C., Piluso V., and Rizzano G., 2000, "Structural Steel Semi Rigid Connections - Theory, Design and Software".

Franssen, J.M., Kodur, V.K.R., and Mason J., 2005, “User's Manual for SAFIR-2004: A Computer Program for Analysis of Structures Submitted to the Fire", University of Liège, Department of Mechanics and Structures, Belgium.

Guo, S.X., and Li, G.Q., 2008, "Analysis of Restrained Steel Beams Subjected to Heating and Cooling Part II: Validation and Parametric Studies", Steel and Composite Structures, Vol. 8, No. 1, pp. 19-34.

Huang, Z., Burgess, I.W., and Plank, R.J., 2004, "3D Modelling of Beam-Columns with General Cross-Sections in Fire", Proceedings of 3rd International Workshop on Structures in Fire, Ottawa.

Huang, Z.H., Burgess, I.W., and Plank, R.J., 2009, "Three-Dimensional Analysis of Reinforced Concrete Beam-Columns in Fire", Journal of Structural Engineering - ASCE, Vol. 135, No. 10, pp. 1201-1212.

Iu, C.K., Bradford, M.A., and Chen, W.F., 2009, "Second-Order Inelastic Analysis of Composite Framed Structures Based on the Refined Plastic Hinge Method", Engineering Structures, Vol. 31, No. 3, pp. 799-813.

Iu, C.K., Chan, S.L., and Zha, X.X., 2007, "Material Yielding by Both Axial and Bending Spring Stiffness at Elevated Temperature", Journal of Constructional Steel Research, Vol. 63, No. 5, pp. 677-685.

Landesmann, A., 2010, "Plastic-Hinge Approach for Inelastic Analysis of Steel Concrete Framed Structures", Journal of Constructional Steel Research, Vol. 66, No. 3, pp. 323-334.

Landesmann, A., Fratti, J.M., and Batista, E.M., 2009, Advanced Analysis of Semi-Rigid Composite Structures under Fire Conditions", Proceedings of SSRC Annual Stability Conference, Phoenix/USA, pp. 109-128.

Liew, J.Y.R, Tang, L.K., Holmaas, T., and Choo, Y.S., 1998, "Advanced analysis for the assessment of steel frames in fire", Journal of Constructional Steel Research, Vol. 47, No. 1-2, pp. 19-45.

Liew, J.Y.R., Tang, L.K., and Choo, Y.S., 2002, "Advanced analysis for performance-based design of steel structures exposed to fire", Journal of Structural Engineering - ASCE, Vol. 128, No. 12, pp. 1584-1593.

Mao, C.J., Chiou, Y.J., Hsiao, P.A., and Ho, M.C., 2010, "The stiffness estimation of steel semi-rigid beam-column moment connections in a fire", Journal of Constructional Steel Research, Vol. 66, No. 5, pp. 680-694.

Mourão, H.R., and Silva, V.P., 2007, "On the behavior of single-span steel beams under uniform heating", Journal of the Brazilian Society of Mechanical Sciences and Engineering,Vol. 29, No. 1, pp. 115-122.

Papadopoulos, P.G., Papadopoulou, A.K., and Papaioannou, K.K., 2008, "Simple nonlinear static analysis of steel portal frame with pitched roof exposed to fire", Structural Engineering \& Mechanics, Vol. 29, No. 1, pp. 37-53.

Ramberg W, Osgood WR., 1943, "Description of Stress-Strain Curves by 3 Parameters", Technical Report 902, National Advisory Committee for Aeronautics (NACA). 
Simões, L.S., Santiago, A., and Vila Real, P., 2001, "A Component Model for the Behavior of Steel Joints at Elevated Temperatures", Journal of Constructional Steel Research, Vol. 57, pp. 1169-1195.

Wang, W.-Y., Li, G.-Q., and Dong, Y.-L., 2008, "A Practical Approach for Fire Resistance Design of Extended End-Plate Joints", Journal of Constructional Steel Research, Vol. 64, pp. 1456-1462.
Yang, K.C., Chen, S.J., and, Ho, M.C., 2009, "Behavior of beam-tocolumn moment connections under fire load", Journal of Constructional Steel Research, Vol. 65, No. 7, pp. 1520-1527.

Yu, X., Huang, Z., Burgess, I.W., and Plank, R.J., 2008, "Nonlinear analysis of orthotropic composite slabs in fire", Engineering Structures, Vol. 30, No. 1, pp. 67-80. 